THURSDAY, AUGUST 19, 1875

\section{THE SCIENCE COMMISSTON REPORT ON THE ADVANCEMENT OF SCIENCE}

$\mathrm{T}^{\mathrm{N}}$ our last issue we published the substance of the 1 Eighth and final Report of the Royal Commission on Science, presicled over by the Duke of Devonshire, which inclucles the measures deemed by that body necessary for the advancement of science in England.

We now propose to lay before our readers a summary of the evidence on the above branch of the investigation undertaken by the Commission. It must be borne in mind that the evidence given on this topic fills a Blue Book of more than 400 closely printed pages, and the extracts from it with which the Commissioners fortify the Report now under notice fill some forty pages. These extracts have been selected with obvious impartiality. The further compression which it must undergo in order to fit it for our columns must necessarily weaken the force of the testimony borne by a cloud of able witresses. All we can hope to do, within our limits, is to give an idea of some of the salient points established, and of the general tendency of the whole.

Adhering to the subdivision, adopted by the Commission, under four principal heads, we proceed to

\section{I.-The Scientific Work carried on by Departments of the Government.}

The following enumeration of State Scientific Institutions now existing, together with that of the various Departments responsible for them, is given on the authority of the Royal Commission :-

Topographical Survey [Treasury (Office of Works)].

Hydrographical Survey [Admiralty].

Geological Survey [Privy Council].

Astronomical Observations :-

Greenwich and the Cape of Good Hope [Admiralty]. Edinburgh [Treasury (Office of Works)].

Meteorological Observations :Greenwich [Admiralty].

Edinburgh [Treasury (Office of Works)].

The Meteorological Office.

[The Meteorological Office is not administered by any Public Department, but is directed by a Committee, which, although appointed by the Royal Society, is independent of that body.]

Botany.--Royal Gardens, Kew ; Botanic Garden, Edinburgh ; Botanic Gardens, Dublin [Treasury (Office of Works)].

The Chemical Department of the War Office.

The Standards Department of the Board of Trade.

Analogous work is carried on in some of the colonies and foreign possessions by departments of their respective Governments.

In one case, that of the Royal Observatory, Greenwich, the work is examined into and reported on to the Admiralty by a Board of Visitors composed of men of science.

This extraordinary list is substantially that with which Col. Strange opened his evidence as the foundation on which the present demands for reform must be based. It establishes conclusively three most important points. (I) That the State does, and therefore should, actively aict scientific research. (2) That it does so partially, many

VOL. XII.-No, 303 essential branches being without aid. (3) That a divided administration such as this list of six or seven departments concerned with science indicates, cannot possibly secure harmony, systematic efficiency, or the extension which, as knowledge and the wants of the nation advance, may be requisite.

The Commissioners then add the following statement, showing the annual charges borne by imperial funds, at the present time, to defray the expenses of such of these various investigations as appear separately in the Estimates for the year 1874-75:-

Topographical Survey (excluding mili-

tary pay of men employed) $\quad \ldots \quad \ldots \quad £ 1$ 1 32,000

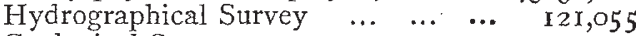

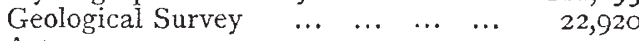

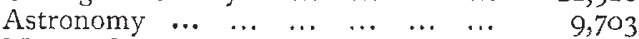

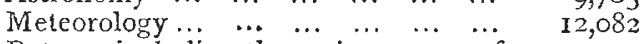

Botany, including the maintenance of Botanical Gardens as places of public recreation $\quad \ldots \quad \ldots \quad \ldots \quad \ldots$

Standards Department of the Board

$$
\begin{array}{llllllll}
\text { of Trade } & \ldots & \ldots & \ldots & \ldots & \ldots & \ldots & 2,063
\end{array}
$$

In addition to these recurring charges, sums are voted from tirre to time for various expeditions and for experimerts incidental to the services of the various departments, such as the investigations concerning the causes and processes of clisease carried on under the direction of the Lords of the Privy Council, and the various experimental researches carried on for the army and navy.

Even if no questions of completeness or extension were raised, the fact of an expenditure, reaching probably about half a million annually, without any pretence of a system to regulate it, is one in itself deserving very serious consideration.

As to the insufficiency of our present administrative arrangements, we have valuable evidence from several Government officials and gentlemen engaged in national works.

Sir Henry Rawlinson, a member of the Indian Council, states that in that Council they perpetually have references before them which they are unable to deal with. He adds :-

". . . We have, for instance, Sir William Baker upon the Council, and General Strachey and Colonel Strange, both attached to the office; yet, notwithstanding their valuable aid, there are many subjects referred to us with which we are quite incompetent to deal."

He then refers to the following subjects among others : - The Manufacture of Iron and Steel in India; the Efflorescence of Soda on Irrigated Land; the Fermentation of Beer, "which may involve a loss of 200,000 . or $300,000 l$. a year to the British Government ;" the question of Drought arising from the Destruction of Forests; the Construction of Harbours and of other Hydraulic Works; the Founding of Brass Guns; Tidal Observations; the Publication of Works on the Flora and Fauna of India ; Geological and Trigonometrical Surveys; Sea Dredging; and Observatories.

He points out that many of these questions are practical and economical, but that still there is a scientific element in almost all of them, and he adds :-

"References on all these subjects are constantly coming home, and we have no means of answering them in our own body, while it is very unsatisfactory to be obliged to 
send out for gratuitous information. We do sometimes, it is true, apply to individuals and sometimes to societies, but in very many cases, I am afraid, the questions are shelved, because there is no competent and authoritative body to refer to."

Capt. Douglas Galton, of the Office of Works and Public Buildings, thinks that, as a rule-

"... Our statesmen do not appreciate properly the value of scientific advice or scientific inquiry, and that they are very much fonder of experiments made upon a large scale with no defined system, than they are of experiments which have been brought out as the result of a carefully studied previous inquiry. I think that an enormous amount of money was wasted in the case of the inquiry into armour plates, both for ships and forts. In that case the Government appointed a partly scientific committee, but it was mixed up with other persons who were not scientific; and instead of commencing a series of experiments upon a small and clearly defined scale, from which they could have drawn conclusions for making their larger experiments, they began by firing at any plates that were offered to them which had no relation one to another, either in their relations to the guns or to the form of backing, or in any other way, and consequently it was difficult to draw useful calculations from thenn."

Mr. Froude, who was a prominent member of the late Committee on Naval Designs, and who is now devoting his whole time without remuneration to the investigation of the proper forms of ships of war, states that if, at an earlier time, a laboratory had existed, and proper experiments had been made, enormous sums would have been saved which have been expended in the actual construction of ships, or, as he terms it, in "experiments on the scale of twelve inches to a foot ;" and that definite results would have been arrived at with less loss of time.

It will be seen from the evidence of General Strachey that he also disapproves of the mode in which Government is at present advised on questions of science, especially on the ground of the absence of scientific training in the political and official classes of this country.

Sir Wm. Thomson has given the following evidence :-

"... With a vast amount of mechanical work which is necessarily undertaken by the Government, and which is continually in hand, questions involving scientific difficulties of a novel character frequently occur; questions requiring accurate knowledge of scientific truth hitherto undeveloped are occurring every day. In both respects the Government is at present insufficiently advised, and the result is undoubtedly that mechanical works are sometimes not done as well as they might be done, that great mistakes are sometimes made; and again, a very serious and perhaps even a more serious evil of the present system, in which there is not sufficient scientific advice for the Government, is the undertaking of works which ought never to be undertaken."

"Are you able to point cut any instances which you have in your mind of mistakes which you think have occurred from the want of good advice on the part of the Govermment?-One great mistalse undoubtedly was the construction of the Captain, and I believe that a permanent scientific council advising the Government would have made it impossible to commit such a mistake. They would, in the very beginning, have relieved the Government from all that pressure of ignorant public opinion which the Government could not possibly, in the present state of things, withstand."

The present system of Special Committees is objected to by Sir Willan Thomson, and by other competent witnesses.
Sir William Thomson thinks "that a single body would be better than a number of small commitlees for ativising the Government on the great variety of questions which from time to time would be likely to arise."

Admiral Richards, late hydrographer of the Admi. ralty, is of opinion that--

"The members of such committees must be selected more or less to fulfil certain political conditions, and that, as a rule, they would come new to the subject that they were going to consider, and I do not believe that the Commission which sat on the Naval Designs the other day was a very successfui one. I do not know that any great advantages have arisen or are likely to arise from it."

Mr. Froude, in reply to the remark, "You do not consider committees of that kind to be a very satisfactory way of proceeding?" thus states his objection to the present system:-

"I do not think so, because they have to find out the dream and the interpretation both, which is al ways a difficulty. They have to feel their way to a locks standi, which would already be possessed by a Council habitually operating with reference to the subject."

Additional examples of these defects are given, not only by these witnesses, but also by others, whom we shall quote when dealing with the proposed remedies.

Evidence was taken by the Commission as to the insufficiency of the present appliances for investigation. The attention of the Commission was especially directed to the want of laboratories for the use of the officials charged with scientific investigations urgently required fo: the economical management of the public departments.

$M r$. Anderson, the superintendent of machinery at Woolwich, who has been responsible for the expenditure of "very nearly $3,000,000 \%$ of public money," points out that there are no means at the disposal of State servanis to enable them to investigate questions on which large ex. penditure depends. With special regard to his own department he states :-

"There is a very great deal which I should like to see taken in hand systematically. .... There is much that we are in the dark about; we are groping in the dark in almost everything at present."

".... Although we know a very greấ cleal with regard to iron, cast, wrought, and in the condition of steel there is yet very much which we do not know, and $I$ an persuaded that if we could with certainty treat orclinary cast iron in the way that we sometimes do nearly by chance, we would do away with three-fourths, or a very large proportion of the wrought iron which is now used in this country, and we should use cast iron."

He next refers to another question of great importance to almost all the public departments :-

". . There is another very important subject which I might mention to the Commission. Some twenty years ago we were using ten or twelve pounds of coal per horse-power per hour, and the majority of engines still require six pounds, but by the improvements that have taken place we are now down to two pounds. There is a little engine at work now in the London district which is working at 13 pounds. There is a great gulf yet between getting steam-engines that will work at $x \frac{3}{4}$ pounds per horse-power per hour, and the point where we are now ; I mean getting that done practically : but I believe that if the right man, or two men, were told off to thoroughly investigate this subject, and not to stop working until they had brought it to a practical shape, we could in ten years from this time get down to one pound 
per horse-power per hour. I see that there are very many leakages or loss in steam-engines in the very best way that we make them at present. The knowledge that was gained by Joule's experiments a few years ago seems to me to have been of immense value. Those experiments that he carried out for himself were the sort of thing which I think the Government should have done for the sake of the country. He did more to make engineers thoroughly dissatisfied with their present knowledge with regard to what they can do with steam than anything which had been done before. I believe that what Mr. Joule did will do more for this country than even what James Watt did. The part that James Watt took was very great, and the world gives him full credit for it, but the world is scarcely willing to give credit to Joule for: what he will do; but he has made all engineers dis. satisfied. They know that the best steam-engine is not doing one-sixth of the work which it ought to do and can do. That is a sad state of matters to be in when we know that we are so far wrong, but yet no one will go to the trouble of going to the end of the question so as to improve the steam-engine as it might be done; in fact, it will cost a great deal of trouble and a great deal of expense, I have no doubt."

With regard to the question whether it is "desirable that the Government should establish any laboratories for carrying on those investigations," he thus stated his opinion:--

"I should like to see a grand laboratory fitted with everything that would go towards the investigation of such matters, and at the same time a testing apparatus for getting at the physical facts as well. To get up the proper plant would be very expensive, but still I should like the nation to have it, so that any public department could go to this same laboratory and ask them for assistance to invesígate any doubtful point."

Mr. Anderson's evidence finds a parallel in that given by Mr. E. J. Reed, M.P., late Chief Constructor of the Navy. He says :-

"I think that there are many branches of science remaining undeveloped at present, the development of which would be of great advantage to the country. I base that opinion partly upon the experience which I acquired at the Admiralty, in which I continually found that great and important questions were undeveloped for the want of organisation and of the means of developing them."

"... A second illustration which I should like to give is this: the present condition of the marine steam -engine and boiler is very unsatisfactory. It is unsatisfactory to such an extent that I believe if the manufacture of iron and steel were improved with reference to its use in the construction of engines and boilers, and if improved material were applied by improved methods, a saving of one-half of the present weight would be attained; and when I say one-half, I know that I am speaking greatly within the limits which some persons who have thought very much about this question would be prepared to express. Of course, if that be so, if we are carrying about in our mercantile and other steamships twice the weight which is essential for the production of the power, that is so much taken off either from the further power and speed which might be obtained, or from the freightage and commercial value of the vessel.

"I may mention that in the manufacture of shafts, for instance, of the marine engine and of stern posts, and other large forgings for ships, the method of production is comparatively rude, and it very much needs development. . . . So much has the subject been neglected, that at this moment I have the responsibility of seeing some very large forgings indeed made for certain ships, and the most effectual manner in which I can give effect to my responsibility is that of selecting the very best working smith that I can find, and putting him into the manufactory where those things are being made, for him to do the best that his experience enables him to do, in order to see them properly constructed. I believe that if a regular independent scientific investigation were applied to a manufacture of that nature, enormous advantage would at once result."

The Standards Department of the Board of Trade is another department requiring advice in varied scientific subjects. The Warden of the Standards (Mr. Chisholm) states that there is no scientific authority to which he is entitled to appeal.

Sir William Thomson, in reference to the subject of standards, says :

"The conservancy of weights and measures is a subject involving questions of the most extreme scientific nicety. Faraday made statements showing how completely unknown at present are the properties of matter upon which we depend for a permanent standard of length. One of the very first objects that should be undertaken in connection with the conservancy of the standards of weight and lerigth is secular experiments, on the dimensions of metals and solids of other classes under various conditions of stress, temperature, and atmosphere. Those would involve scientific experiments of an extremely difficult character, and also operations extending from year to year. There ought to be just now a set of experimental specimens of solids laid up which should be examined every year, or every ten years, or every fifty years, or every hundred years, the times when observations are to be made from age to age being regulated by the experience of the previotis observations. This would not be a very difficult or expensive things to institute in such a way as eventually to obtain good results, but it would be an operation of a secular character, which could only be carried out by the Government."

Dr. Frankland thus refers to the various requirements of Government involving chemical investigations :-

"... The State requires many important investigations to be carried on. Such investigations are being continually conducted in buildings often very ill-adapied for the purpose, and which are fitted up for the purpose at a great cost. The laboratory of the Rivers Commission, for instance, which we have occupied for four years, was constructed in a house in Victoria Street; a rent of $200 \%$ a year is paid for it, and it is literally nothing more than a moderate sized room, and two smaller ones, very ill-adapted for the purpose. Consequently, this laboratory is not so efficient as a building erected for the express purpose of conducting such investigations would be."

\section{We pass now to}

\section{II.- The Assistance given by the State toruards the Promotion of Scientific Research.}

It may be convenient to consider the assistance given by the State towards scientific research as being either permanent or occasional.

Our museums of natural history are examples of the first. These afford to the students of those branches of science aid analogous to that afforded to students of literature and art by our national libraries and galleries.

No similar facilities are provided for the student of the physical sciences-such collections of instruments as exist being wholly inadequate both as to character and completeness. Moreover, as the Commissioners remark, "a mere collection of instruments, however complete, without working laboratories, is of little use to the student 
of the experimental sciences, and as there are no public laboratories available for the researches of private investigators, it may be said that in many branches of experimental science the State affords no permanent material aid to such investigators."

Assistance of a permanent description is also afforded to learned societies, by providing them with apartments free of rent, or with annual grants of money in lieu of such accommodation: the sum of $500 \%$.granted annually to the Royal Geographical Society under certain conditions is an instance of such a grant.

We may regard as a permanent aid to science the grant of $x, 000 \%$. for researches carried on by private individuals, which is annually voted by Parliament, and administered by a Committee of the Royal Society.

The first proposal for such a grant was contained in a letter (dated October 24th, I849) from Earl Russell then (Lord John Russell) to the then President of the Royal Society (the Earl of Rosse), and was to the following effect :-

"As there are from time to time scientific discoveries and researches which cost money and assistance the stuclents of science can often but ill afford, I am induced to consult your lordship, as President of the Royal Society, on the following suggestion :-

"J propose that at the close of the year the President and Council should point out to the First Lord of the 'Treasury a limited number of persons to whom the grant of a reward, or of a sum to defray the cost of experiments, might be of essential service. The whole sum which I could recommend the Crown to grant in the present year is $I, 000 l$, nor can I be certain that my successor would follow the same course; but I should wish to learn whether, in your lordship's opinion and that of your colleagues, the cause of science would be promoted by such grants."

Lord Rosse, in reply to the proposal made by Lord J. Russell, expressed his personal opinion that the judicious employment of grants in the way proposed "would very materially promote the advancement of science;" and of the two alternatives, namely, expending the $\mathrm{I}, 000 \mathrm{l}$. in rewards, or appropriating it to the payment of the expenses of experiments, he preferred the latter, indicating his reasons as follows :-

"There are often details to be worked out before it is possible to employ usefully newly discovered principles. In many of the sciences reductions are required before observations can be made use of. Both in science and art, facts technically called constants are the materials of discovery ; to determine them accurately is of great importance. Now in all these cases, and in many others, the work to be done is laborious and expensive, and as it adds but little comparatively to the fame of the individual, it especially requires encouragement."

With regard to this "Government grant" Sir Edward Sabine in his evidence says : . . "I suppose that the $1,000 l$, in one year was designed as an experiment to try the matter in the first instance. I always understood that Lord Russell contemplated that the sum would be augmented if the plan were found to work well."

No change however has been made either in the amount of the grant or in its mode of distribution since its first establishment.

As examples of the second-occasional-kind of aid, expeditions for special researches, outfits of ships, and apparatus and grants of money for such researches, are mentioned. Great as is the value of these contributions, the Commissioners pointedly remark that "they do not appear to be granted or refused on any sufficiently welldefined principle."

The lesson, indeed, which crops up throughout the invaluable investigations of this Commission, is that there is a total want of system in almost all that we do, as a nation, towards advancing scientific research.

( $T$ o be continued.)

\section{THE ENCYCLOP EDIA BRITANNICA}

The Encyclopadia Britannica; a Dictionary of Arts, Sciences, and General Literature. Ninth Edition. Vol. II., ANA to Ath. (Edinburgh: Adam and Charles Black, 1875.)

T reviewing the first volumel of this new edition of the 1 "Encyclopædia" (NATURE, vol. xi. p. 343), we were obliged, by want of space, to omit more than the briefest possible remarks upon the general plan of the work. The conspicuous and increasing success of the work is apparently a sufficient answer to those who would find fault with the form of arrangement peculiar to this "Encyclopædia." Among the considerable number of Cyclopædias which have been produced in Great Britain during the last hundred years, this one, almost alone, has been reproduced in a number of successive editions, growing in excellence and reputation, and many people might take this fact to be a sufficient proof that it is well designed to meet $\mathbf{a}_{r}$ general want. But this success must surely be due in great degree to the eminence of the contributors, to the slkill of the editors, or to any circumstance rather than the scheme of the work.

We have always been unable to comprehend the exact raison d'être of a cyclopædia which is neither strictly aiphabetical nor strictly systematic. The "Britannica " may be compared to a solid body of pudding with plums in the form of excellent treatises disposed here and there. Now we entirely fail to perceive any convenience in this mode of construction. That it is not very suitable for the purpose of simple reference seems to be proved by the need of a full index to the whole of the volumes. Nor, if a person wishes to use one of the articles for careful continuous study in the manner of a text-book, is it convenient to have it embedded in a very heavy quarto volume, one of a large and costly series. Many valuable and highly useful treatises are in fact buried in this "Encyclopædia," and are hardly available for purposes of general reading. That this is so has been confessed by the separate publication of some of the principal treatises in former editions ; those, for instance, by Sir John Herschel on "Physical Geography," and on "Meteorology."

Cyclopædias have varied in form from the purely alphabetical ones, best represented now in "Chambers" Cyclopædia," which approximates to the character of a dictionary, to "Lardner's Cyclopædia," in which each subject was treated in a distinct and handy volume. Coleridge tried to combine the two principles in the "Encyclopzdia Metropolitana," in which all sciences and branches of knowledge were to be expounded in a series of elaborate treatises, arranged according to logical method, while an alphabetical dictionary of reference 